\title{
Effects of Superstructure Components on CWR Track Buckling
}

\author{
Masoud Fathali ${ }^{1 *}$, Fereidoon Moghadas Nejad ${ }^{2}$, Amir Azadbakhsh ${ }^{1}$ and Vahid Nejad Seifi ${ }^{2}$ \\ ${ }^{1}$ School of Railway Engineering, Iran University of Science \& Technology, Iran \\ ${ }^{2}$ Department of Civil and Environmental Engineering, Amirkabir University of Technology, Iran
}

*Corresponding author: Masoud Fathali, Postdoctoral Fellow, School of Railway Engineering, Iran University of Science \& Technology, 16846, Tehran, Iran.

Received Date: August 31, 2019

Published Date: September 13, 2019

\begin{abstract}
Track buckling is formation of large lateral misalignments mainly due to high compressive thermal stresses in continuous welded rail (CWR) tracks and often results in catastrophic derailments. Recognizing the actual behavior of this phenomenon requires complex interaction simulation of track components in vertical, lateral and torsional modes; however, most studies have restricted themselves to either vertical or horizontal planes, to make the analysis tractable. In the present study, the effects of track components including rails, sleepers, fastening systems and ballast materials on lateral stability of CWR tracks are determined, utilizing a developed 3D model. The validity of the model is verified through comparisons with CWERRI program results and other experimental works. Parametric studies have been conducted for both straight and curvilinear tracks. The results indicate that both parameters of ballast lateral resistance and type of rail have considerable influences on railway buckling behavior Moreover, torsion stiffness of fastening system, type of sleeper and ballast stiffness in vertical and longitudinal directions have lower impacts.
\end{abstract}

Keywords: Buckling; Stability; CWR; Track; Superstructure; Temperature

\section{Introduction}

Continuous welded rail (CWR) is replacing jointed track for enhancing the advantages of better economics of maintenance and ride comfort. A well-known risk with CWR, however, is its potential for buckling due to high thermally induced compressive loads, with possible train derailment and track losses consequences [1]. Hence, recognition of important factors and paying attention to the effects of different parameters would be necessary in lateral stability of the tracks. Buckles are typically caused by a combination of three major factors [1,2]: high compressive forces, weakened track conditions, and vehicle loads (train dynamics). Compressive forces result from stresses induced in a constrained rail by temperatures above its "stress free" state, and from mechanical sources such as braking, rolling friction and wheel flanging on curves $[3,4]$. Weakened track conditions impacting the track buckling potential include reduced track resistance, lateral alignment defects, and lowered rail neutral temperature. Track resistance is the ability of the ballast, sleepers and fasteners to provide lateral and longitudinal strength to maintain track stability [5,6]. Wheel loads and train action (dynamic uplift wave) also tend to increase its size to the levels which trigger the buckling process $[7,8]$.
Applying simple Beam, 2-D rail-sleeper models and threedimensional modeling and calculations, several researches have been accomplished for investigating the buckling behavior of CWR tracks, including primary and complementary classic methods for straight and curvilinear tracks [9-11], parametric study of thermal stability on CWR [12,13], sandwich model [14], monitoring rail road tracks [15], component materials [16], and some other scattered studies [17-19]. These models, however, have their inherent shortcomings for the CWR track buckling analysis, and most studies restrict themselves to either the vertical or the lateral plane [20]. Also, the importance of the effects of superstructure components has been less considered in comparison with the geometrical and operational conditions. Therefore, a more advanced threedimensional theoretical model for track buckling analysis is needed. The objective of this study is to develop a new, comprehensive, three dimensional CWR track model to evaluate the effects of different superstructure components including rails, sleepers, fasteners and ballast layer for a three-dimensional stability analysis. The model is developed through APDL programming code of the ANSYS software. The main advantage of this program, unlike the other 
numerical models, is the consideration of the whole of the track to increase the accuracy and to determine the sensitivity of different parameters. Also, for the modeling of direct part of the track at the beginning and the end of the route, the rail element itself is used instead of using the equivalent spring [18], which is more realistic. According to this model, the maximum buckling temperature through the parametric studies of track components is obtained.

\section{Model geometry}

The validity of the present study is strictly verified through a series of comparisons with an existing theoretic model and field results.

\section{Modeling Procedure}

The developed model includes an APDL programming code in AVSYS software which accomplishes a three-dimensional analysis of track buckling with consideration of track geometrical features, mechanical properties of the components and loading conditions.

Figure 1: Track geometrical features.

Table 1: The geometrical features of the model.

\begin{tabular}{|c|c|c|c|c|c|c|c|}
\hline \multirow{2}{*}{ No. } & \multirow{2}{*}{ Parameter } & \multirow{2}{*}{ Description } & \multirow{2}{*}{ Range } & \multicolumn{3}{|c|}{ Reference Values } & \multirow{2}{*}{ Unit } \\
\hline & & & & Straight 1 & Straight 2 & Curvilinear & \\
\hline 1 & XATYPE & Track type & $1-0$ & 1 & 1 & 0 & - \\
\hline 2 & XAIE & Misalignment existence & $1-0$ & 1 & 1 & 1 & - \\
\hline 3 & $\mathrm{XR}$ & Curve radius & $0 \sim 10000$ & 0 & 0 & 400 & [m] \\
\hline 4 & $\mathrm{XL}$ & Track length & $20 \sim 110$ & 50 & 50 & 50 & [m] \\
\hline 5 & $\mathrm{XM}$ & Misalignment length & $1 \sim 17$ & 9 & 9 & 9 & {$[\mathrm{~m}]$} \\
\hline 6 & $\mathrm{XI}$ & Misalignment amplitude & $0.005 \sim 0.05$ & 0.018 & 0.018 & 0.035 & {$[\mathrm{~m}]$} \\
\hline 7 & $\mathrm{XH}$ & Tie spacing & $0.5 \sim 0.65$ & 0.6 & 0.6 & 0.6 & [m] \\
\hline 8 & XG & Track gauge & $1,1.435,1.672$ & 1.435 & 1.435 & 1.435 & [m] \\
\hline 9 & Xhc & Track cant & $0 \sim 0.16$ & 0.1015 & 0.1015 & 0.1015 & [m] \\
\hline 10 & XNHWS & Number of misalignments & $1 \sim 3$ & 3 & 2 & 1 & - \\
\hline
\end{tabular}

In order to investigate the buckling behavior of CWR tracks, both straight and curvilinear lines in a parametric manner are modeled. The parametric curvilinear track model, as shown in Figure 1, is XL long, with a horizontal curve radius of XR and track gauge of XG. The misalignment in the middle is characterized by a half sine wave with a length of XM and amplitude of Xl. Also, for the straight track model, all of the parameters except the curve radius are the same; however, considering the common deficiency of straight tracks [21], the number of misalignments is usually two or three half sine waves. The reference values of geometrical features of curvilinear and straight models are presented in Table 1 (Figure 1) (Table 1).

\section{Mechanical features}

In order to model the track components, different elements are used. The rail is modeled as a mono-symmetric thin-walled open section beam (BEAM 189) that results in the stress-strain curve characteristics as shown in Figure 2A. Also, the rail cross section with an approximately "I" shape is shown in Figure 2B. The type of rail in the reference condition is selected to be UIC60 as the most common type and the other types are verified as mentioned in Table 2 . The elastic and shear modulus values, the coefficient of thermal expansion and the Poisson ratio are considered $2.1 \times 107,8.1 \times 106$ $\mathrm{N} / \mathrm{cm}^{2}, 11.5 \times 10-6 /{ }^{\circ} \mathrm{C}$ and 0.3 , respectively [21] (Figure 2) (Table 2).

Table 2: Properties of the rail cross-sections [19].

\begin{tabular}{|c|c|c|c|c|c|}
\hline Rail Type & $\mathbf{A}_{\mathbf{H}} \mathbf{m m}^{2}$ & $\mathbf{A}_{\mathrm{W}} \mathbf{m m}^{2}$ & $\mathbf{A}_{\mathrm{F}} \mathbf{m m}^{2}$ & $\mathbf{I}_{\mathbf{y}-\mathbf{y}} \mathbf{c m}^{4}$ & $\mathbf{I}_{\mathbf{z - z}} \mathbf{c m}^{\mathbf{4}}$ \\
\hline UIC 50 & 2899 & 1318 & 2169 & 1930 & 314 \\
\hline UIC 54 & 2899 & 1486 & 2590 & 2336 & 419 \\
\hline UIC 60 & 3085 & 1730 & 2856 & 3039 & 513 \\
\hline
\end{tabular}




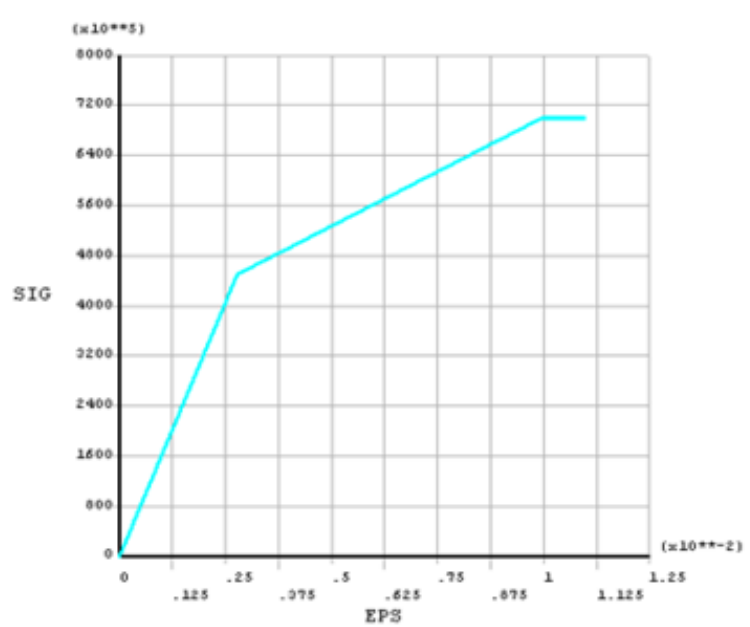

A

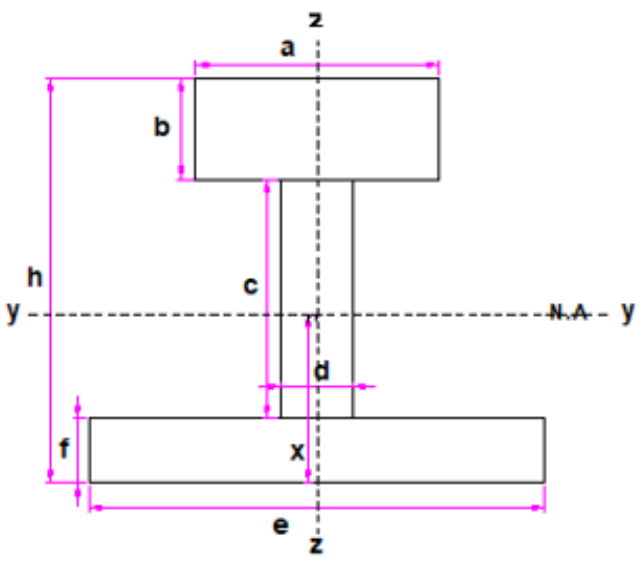

B

Figure 2: Rail model A) Stress-strain curve, B) Defined rail cross section.

The sleeper is modeled by a three-dimension truss element (LINK 8) which is illustrated in Figure 3. As the most common types, both concrete and wooden sleepers weighing 290 and 90 $\mathrm{kg}$ and the elastic modulus of $0.3 \times 107$ and $0.123 \times 107 \mathrm{~N} / \mathrm{cm}^{2}$ are considered, respectively. Also, the cross-sectional area values for the concrete and wooden ties are 389.5 and $264.5 \mathrm{~cm}^{2}$ and the ballast friction coefficients are 0.86 and 1.2, respectively [21]. Modeling the behavior of the fastening system involves using a twonode element with zero length (double node system) in terms of transitional and rotational degrees of freedom, as shown in Figure 3A (Figure 3).

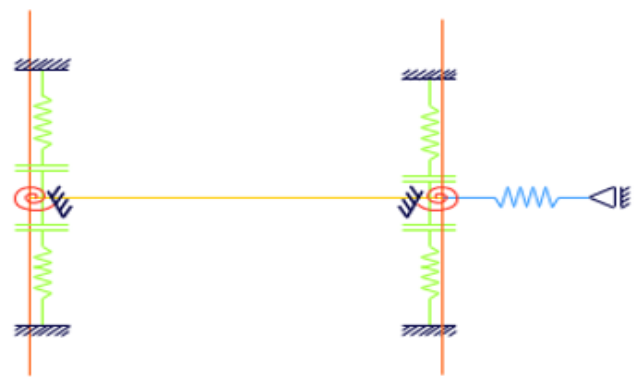

A

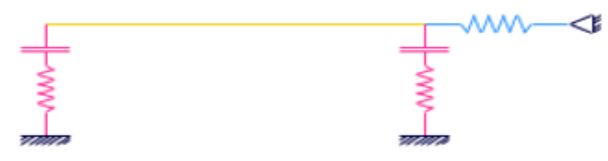

B

Figure 3: Tie model A) Plan view, B) Cross section view.

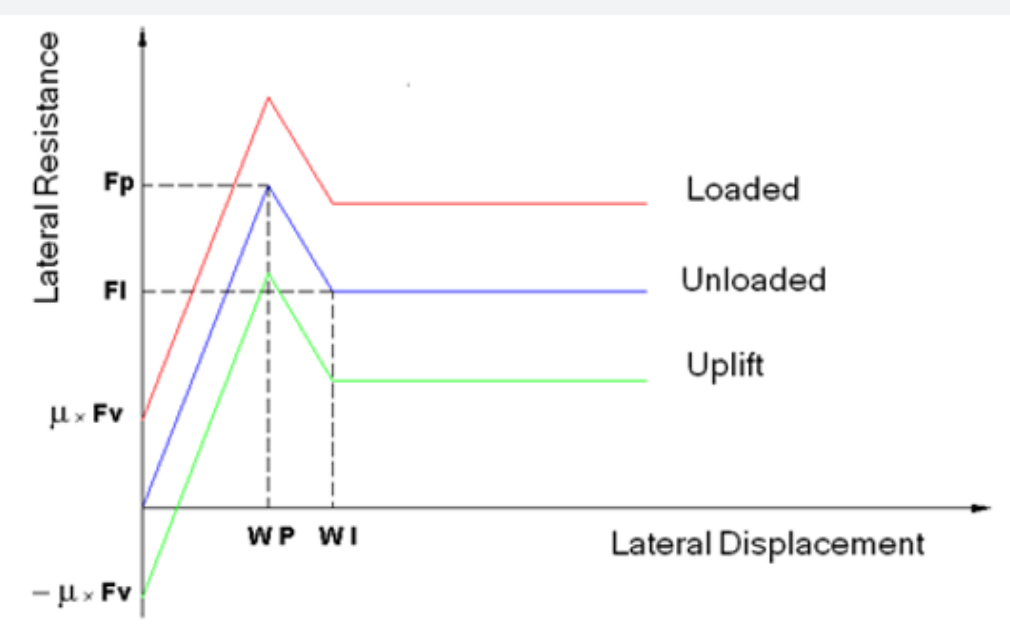

Figure 4: Lateral behavior of ballast material. 
The ballast layer supports the track laterally, longitudinally and vertically. The resistance provided by the ballast and subgrade is a key factor which keeps the CWR track stable. Existing test data indicate that the relationship between displacement and applied force on the sleeper is linear for small, but nonlinear for large displacements [21]. This means that one should consider the ballast not only as elastic but also inelastic. An appropriate idealization of the lateral and longitudinal resistance is important to obtain a reliable buckling and safe temperature. The lateral and longitudinal resistances are considered with an elasto- plastic model as shown in Fig. 4. This model is as linear elastic until the lateral force has reached its peak value, after which the ballast starts softening and then yielding and the plastic deformations start to increase. The procedure of obtaining the parameters in the figure is mentioned in reference 21. In this figure, FP is the peak resistance without considering extra loading due to peak lateral displacement of WP and FL is the limit resistance due to plastic limit displacement of WL. FV is the vertical resistance which is multiplied in frictional coefficient of $\mu$ and added or subtracted based on the loaded or uplift conditions (Figure 4).

In order to simulate the vertical behavior of ballast and subgrade, the contact element (CONTACT 52) is used with a linear behavior as a function of vertical load. Also, the lateral and longitudinal behavior is modeled via combination of nonlinear spring element (COMBIN 39) and the contact element (CONTACT 52). The spring element simulates the lateral behavior through the ballast materials at the end of the sleepers as well as friction between sleeper wall and ballast contact surface. The contact element simulates the friction between the bottom of the sleeper and ballast as a function of vertical load. Therefore, the lateral load- displacement curve of Figure 4 can be easily obtained via these elements. The ranges of material properties for different parameters are presented in Table 3. These values are considered based on the common material properties presented in references 21 and 22 [21,22] (Table 3).

Table 3: The mechanical properties of the model.

\begin{tabular}{|c|c|c|c|c|c|}
\hline No. & Parameter & Description & Reference Value & Range & Unit \\
\hline 1 & XFP & Ballast lateral limit resistance & 17600 & $10000 \sim 26262$ & {$[\mathrm{~N} / \mathrm{m}]$ track } \\
\hline 2 & XWP & Ballast lateral limit displacement & 0.0065 & $0.005 \sim 0.035$ & {$[\mathrm{~m}]$} \\
\hline 3 & XFL & Ballast lateral peak resistance & 9500 & $5500 \sim 14445$ & {$[\mathrm{~N} / \mathrm{m}]$ track } \\
\hline 4 & XWL & Ballast lateral peak displacement & 0.036 & $0.015 \sim 0.05$ & {$[\mathrm{~m}]$} \\
\hline 5 & XKL & Longitudinal stiffness & 3100000 & $10000 \sim 100000$ & {$[\mathrm{~N} / \mathrm{m}]$ track } \\
\hline 6 & XKT & Torsional stiffness & 112000 & $0 \sim 300000$ & {$[\mathrm{~N} / \mathrm{m}]$ track } \\
\hline 7 & XKN & Ballast Vertical stiffness & 68700000 & $26000000 \sim 111000000$ & {$[\mathrm{~N} / \mathrm{m}]$ track } \\
\hline 8 & XNU1 & Contact friction coefficient & 0.86 & $0.86-1.2$ & - \\
\hline 9 & XURPT & Rail type & 3 & $3-2-1-0$ & - \\
\hline 10 & XWS & Tie weight & 290 & $0.02645-0.03895$ & {$[\mathrm{~kg}]$} \\
\hline 11 & XAS & Tie cross section area & 0.03895 & & {$[\mathrm{~m} 2]$} \\
\hline
\end{tabular}

\section{Loading pattern}

The track is loaded vertically by a standard loading pattern of UIC with two bogies, represented by four vertical axle loads of 200
KN each (a reference value), as indicated in Figure 5. Also, the other features of loading conditions are presented in Table 4 (Figure 5) (Table 4).

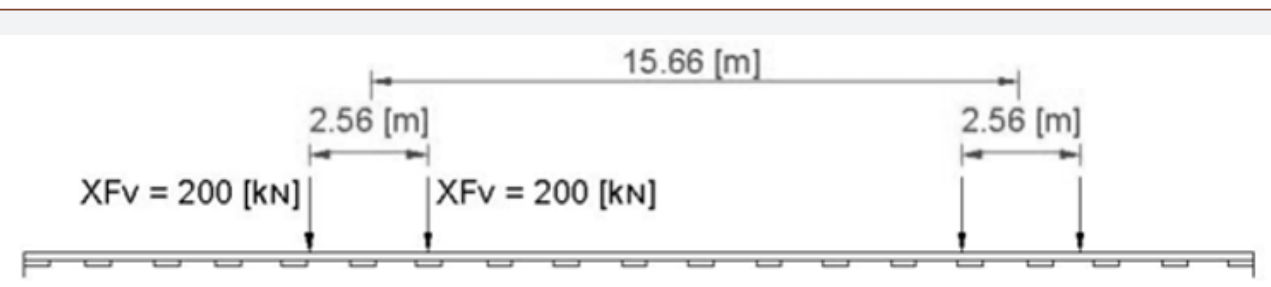

Figure 5: Standard loading pattern of UIC [32].

Table 4: The Loading properties of the model.

\begin{tabular}{|c|c|c|c|c|c|}
\hline No. & Parameter & Description & Reference value & Range & Unit \\
\hline 1 & XTE & Temperature changes & 100 & $0 \sim 100$ & ${ }^{\circ} \mathrm{C}$ \\
\hline 2 & XFV & Axle load & 200000 & $160000 \sim 225000$ & $\mathrm{~N}$ \\
\hline 3 & XV & Vehicle speed & 60 & $0 \sim 100$ & $\mathrm{Km} / \mathrm{h}$ \\
\hline 4 & XDA & Wheel space of bogie & $2 / 56$ & $1 / 8 \sim 3$ & $\mathrm{~m}$ \\
\hline 5 & XI & Center to center space of bogies & $15 / 66$ & $10 \sim 20$ & $\mathrm{~m}$ \\
\hline 6 & XTBSAD & Acceleration / Brake factor & 0 & $0 \sim 25 \%$ & - \\
\hline 7 & XRCF & Track condition factor & $0 / 1$ & $0 / 1-0 / 2-0 / 3$ & - \\
\hline
\end{tabular}




\section{Model Verification}

Using the developed 3-D model and according to the dimensions and properties were explained previously, buckling analyses was carried out on both straight and curvilinear track structures. As illustrated in Figure 6A for the curvilinear model, the whole of the track is deviated out of curve and the buckled wave includes a large half wave at the center and two smaller half waves at the sides. The length of the center half wave is almost the same as the primary misalignment which shows the extension of primary defect. Also, the interception points of center and side waves are located at the beginning and end of the primary misalignment. The smaller half waves have a length of nearly $2.50 \mathrm{~m}$ and the maximum lateral displacements for the center and side waves are $8.36 \mathrm{~mm}$ and 2.32 $\mathrm{mm}$, respectively. The shapes of buckled waves for straight track depend on the number of the considered misalignments in the structure model. Considering two misalignments as illustrated in Figure 7A, two large half waves at the center and two smaller half waves at the sides are resulted with the maximum displacements of $10 \mathrm{~mm}$ and $2.53 \mathrm{~mm}$, respectively. For three misalignments as that of the curve model (see Figure 7B), a large half wave at the center and two smaller half waves at the side are resulted with the maximum displacements of $23.54 \mathrm{~mm}$ and $8.43 \mathrm{~mm}$, respectively. However, there are not any lateral displacement at the beginning and end areas, in comparison to the curve model and hence, the buckling of straight track has resulted just lateral movement of the center of the track.

To verify the validity of the present model, a specific issue with the distinct results from theoretical calculations [18] and field experiments [23] was applied and compared with the results of the developed curved model. As illustrated in Figure 6B, the inclinations of the curves are almost the same, whereas the maximum temperatures and the maximum lateral displacements calculated via the present model are slightly greater and less than the existing models, respectively. As shown in Figure 6B, the form of the buckled wave includes a major semi-wave along with two small ones at the beginning and end. Hence the main reason of this difference is the lateral behavior of the ballast in the middle of the track. Another reason is the modeling of the whole of the track, while the track is simulated by a beam with equivalent springs in the other models (Figure 6,7).
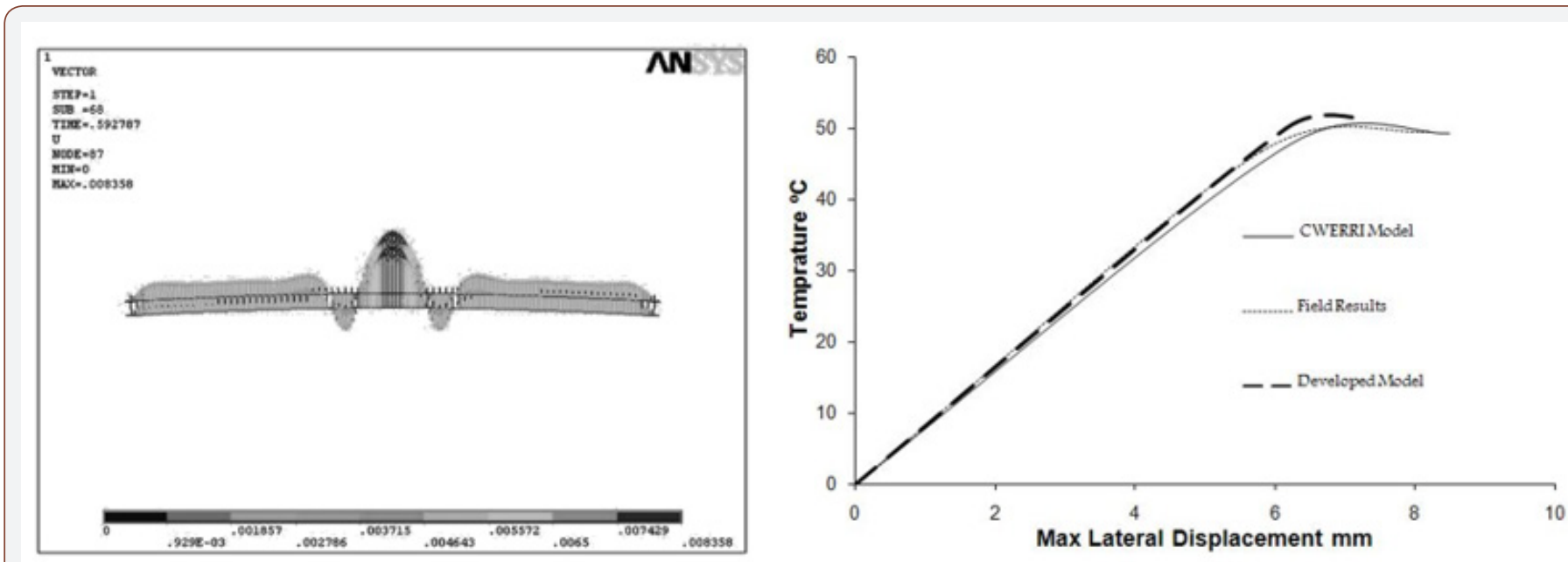

A

B

Figure 6: The curve buckled model, A) The shape of track buckling, B) Verification of the results.

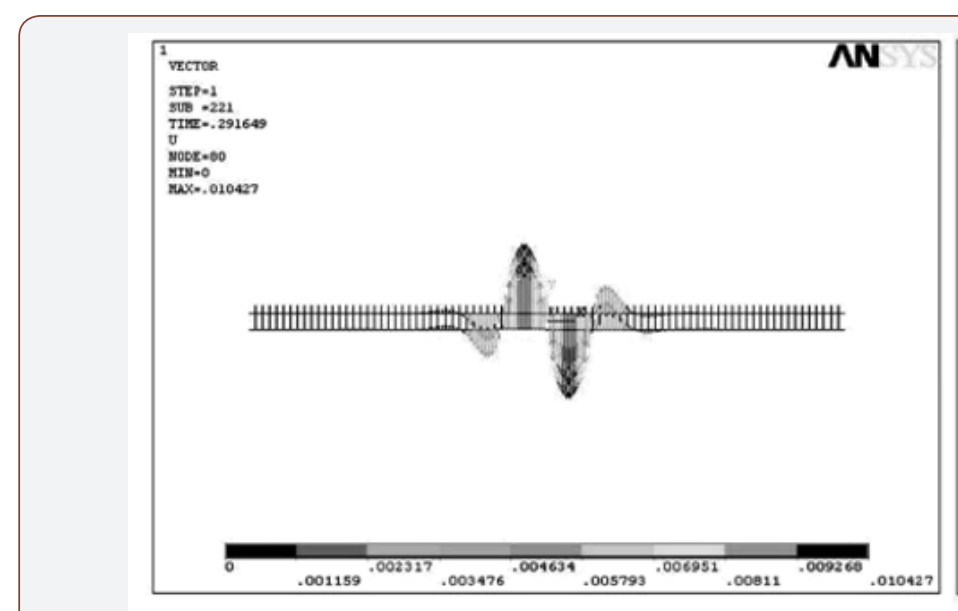

A

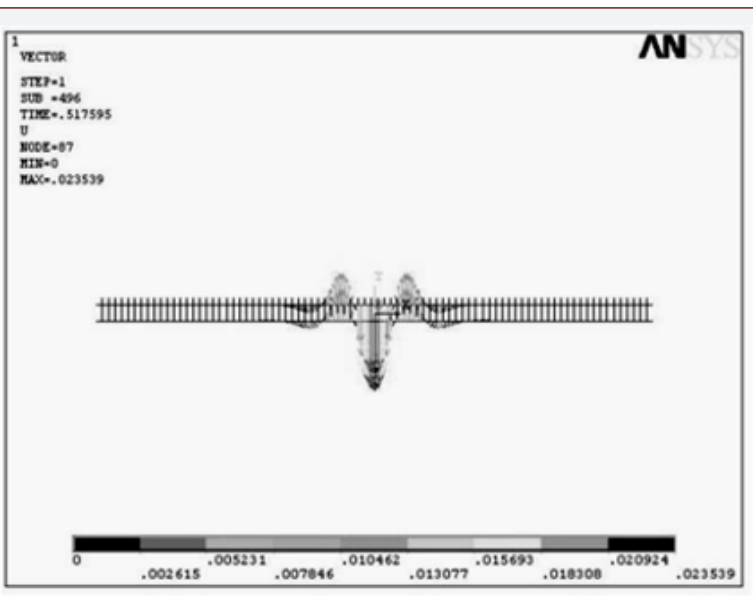

B

Figure 7: The straight buckled model A) two misalignments B) three misalignments. 
Evaluation of Track Components Effects on the Buckling

\section{Behavior}

In track buckling analyses as mentioned, the importance of the effects of superstructure components has less been considered in comparison with the geometrical and operational conditions. In this section, different analyses are presented on superstructure components, based on the developed buckling model and the effects of each component on buckling behavior are discussed.

\section{Rails}

The main cause of the axial forces in CWR tracks is the thermal expansion of rail metal which has an important role in lateral stability of the track. According to the general equations of the computational methods governing track buckling [21], track equivalent moment of inertia along with rails moment of inertia play important roles in preventing buckling behavior. Figure 8A shows the influence of the type of rails on the buckling temperature increase for both straights and curvilinear tracks. Increasing the moment of inertia for the rails (i.e. utilizing stronger rails), the critical buckling load and consequently the maximum temperature will increase. The influence of the type of rails on the maximum lateral displacement is also presented in Figure 8B which shows a decreasing trend as the moment of inertia of the rail is increased (Figure 8).

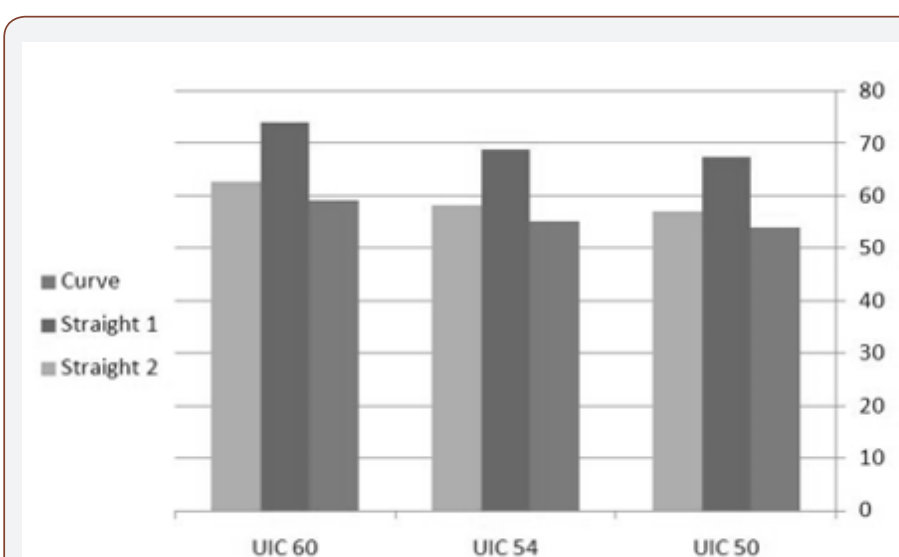

A

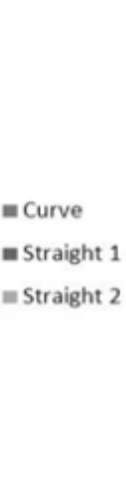

Straight 1 Straight 2

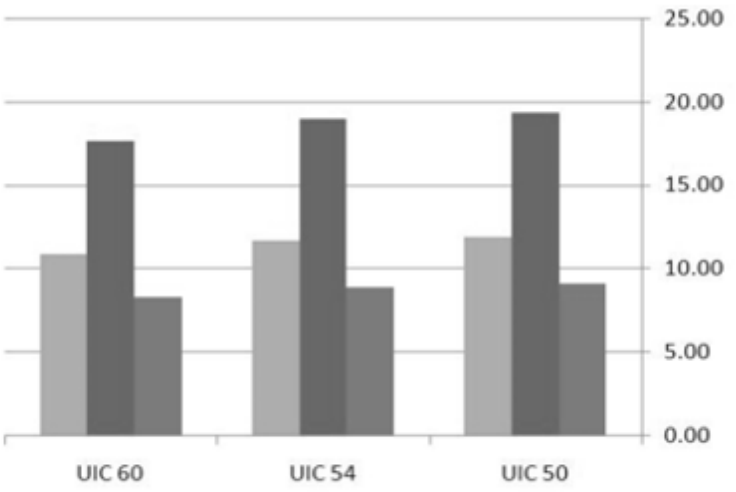

B

Figure 8: Buckling behavior vs. rail types A) Buckling temp. $\left({ }^{\circ} \mathrm{C}\right)$ B) Max. lateral displacement (mm).

As illustrated in Figure 8, with a 57\% increase in rail moment of inertia (i.e. from UIC50 to UIC60), the buckling temperatures for both curvilinear and straight tracks are increased for about 10 $15 \%$ while, the maximum lateral displacements have faced a 8 to $11 \%$ decrease.

\section{Sleepers and fastening systems}

The axial forces of the rails in CWR tracks are transmitted to the ballast layer by means of sleepers and fastening systems. Fig.9 shows the influence of type of sleepers on the buckling behavior of both straight and curvilinear tracks. It is seen that the type of sleeper has a slight effect on buckling temperature and lateral displacement and varies the analyses results for about 2 to $3 \%$. This can be explained such that, although the friction between wooden sleepers and the ballast material is more than concrete sleepers, its weight is less and hence the products of friction coefficients and vertical loads for both of the ties are almost the same (Figure 9).

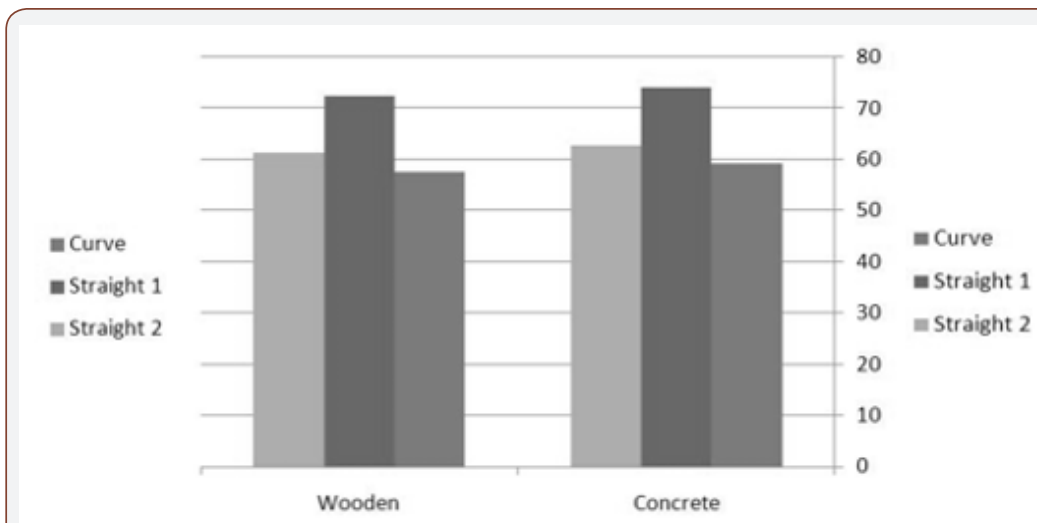

A

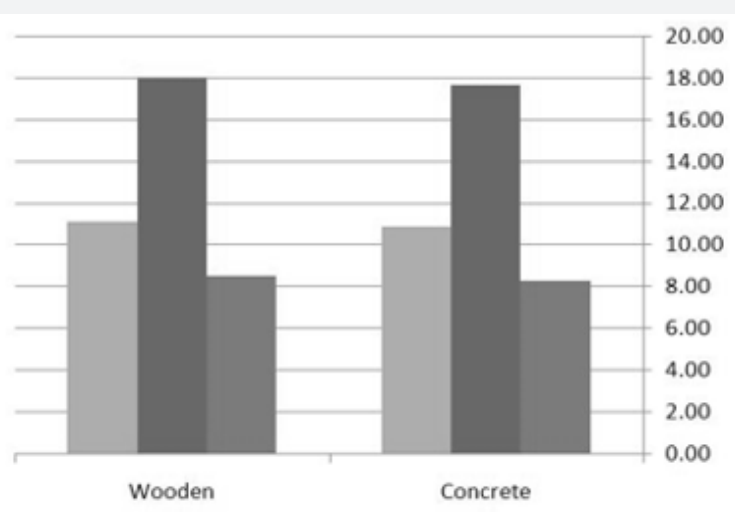

B

Figure 9: Buckling behavior vs. sleeper types A) Buckling temp $\left({ }^{\circ} \mathrm{C}\right)$ B) Max lateral displacement (mm).

Figure 10 also illustrates the influence of torsional stiffness of fastening systems on buckling behavior. As it is shown, increasing torsional stiffness of fasteners affects the buckling temperature a little. In a curvilinear track, the increase of stiffness from 112 to 
$300 \mathrm{KN} / \mathrm{rad}$ in a unit length increases the buckling temperature from $59.27^{\circ} \mathrm{C}$ to $60.41{ }^{\circ} \mathrm{C}(1.9 \%)$ which is because of the increase in the whole track resistance by means of fasteners. For the straight track, an increase in the fastening stiffness to $300 \mathrm{KN} / \mathrm{rad}$ in a unit length increases the buckling temperature to $76.23{ }^{\circ} \mathrm{C}(2.9 \%)$ as well (Figure 10).

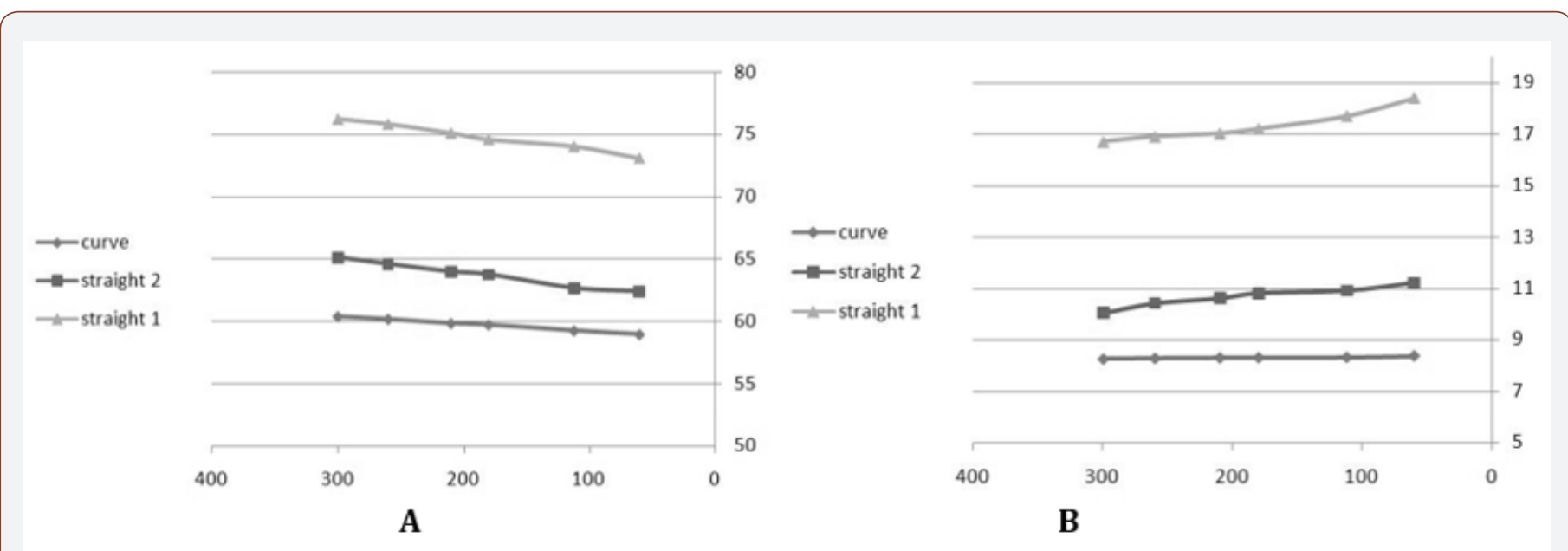

Figure 10: Buckling behavior vs. fastening stiffness A) Buckling temp $\left({ }^{\circ} \mathrm{C}\right) \mathrm{B}$ ) Max lateral displacement (mm).

\section{Ballast materials}

Figure 11 shows the influence of ballast lateral resistance on the buckling behavior of the railway track. As ballast lateral resistance is increased, the whole resistance of the track and hence the maximum buckling temperature increases in a nearly linear manner (Figure 11A). For the curvilinear track, the $49 \%$ enhancement of ballast lateral resistance from 17.6 to $26.2 \mathrm{KN} / \mathrm{m}$ results in a $28 \%$ buckling temperature growth from 59.3 to $76.1^{\circ} \mathrm{C}$. This growth is about $16 \%$ for the straight track which is still a noticeable enhancement. Figure 11B also presents the track lateral displacement via ballast lateral resistance. According to the figure, increasing the lateral resistance of ballast materials leads to the reduction of the lateral track displacement. In the first zone (i.e. ballast lateral resistance of 10 to $14 \mathrm{KN} / \mathrm{m}$ ), the dropping rate is higher, while it gradually reaches a constant value (i.e. ballast lateral resistance of more than $20 \mathrm{KN} / \mathrm{m}$ ). The figure has also a sudden change through the resistances between 14 to $17 \mathrm{KN} / \mathrm{m}$. To come up with the illustrated behavior and for more sense of track lateral behavior, it is better to consider the lateral load-displacement curve of the ballast material. When the lateral resistance is lower than $14 \mathrm{KN}$, the exerted forces through critical sleepers put in the plastic zone of load-displacement curve and hence, with reducing the resistance, the displacement grows and reaches to an asymptote parallel to $\mathrm{Y}$ axis. For resistances more than $20 \mathrm{KN}$, elastic load-displacement curve conditions rule and hence, the plastic displacement would be constant. In the middle part also, the softening zone is achieved and hence the displacement is decreased abruptly(Figure 11).

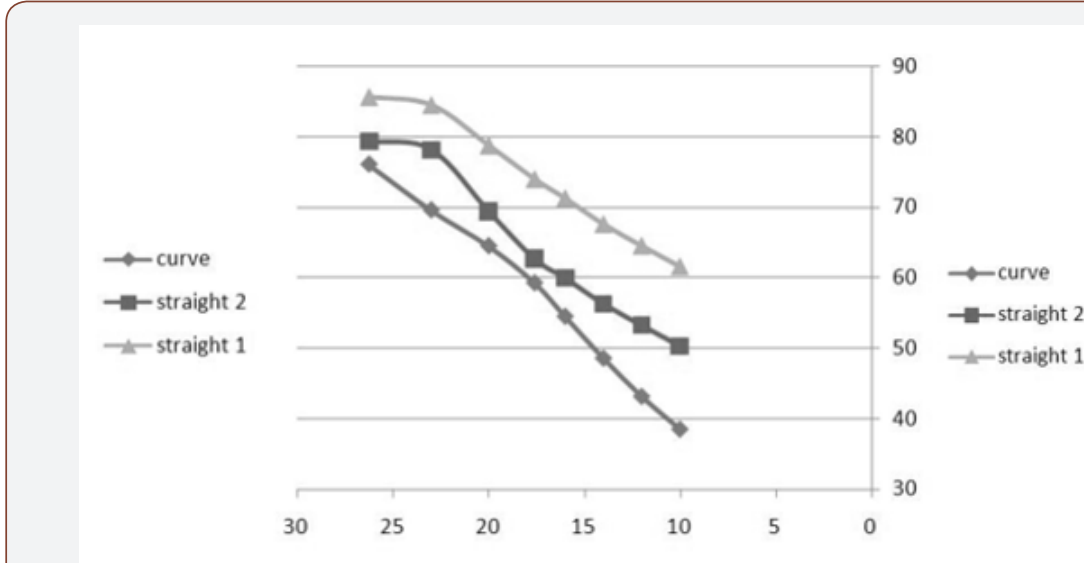

A

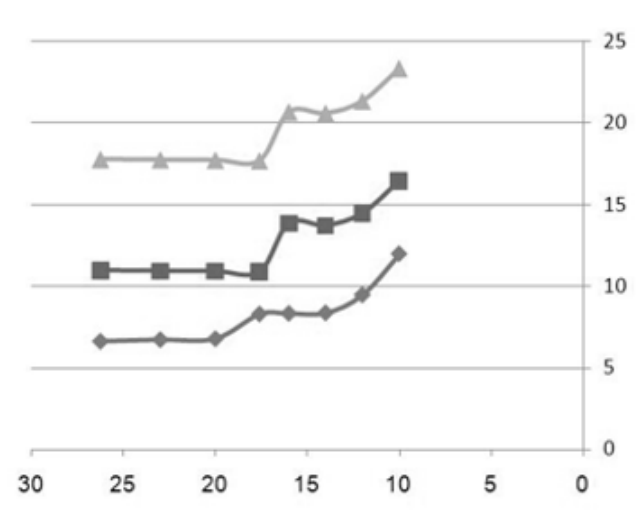

B

Figure 11: Buckling behavior vs. Ballast resistance A) Buckling temp $\left({ }^{\circ} \mathrm{C}\right) \mathrm{B}$ ) Max plastic displacement (mm).

The changes in maximum buckling temperature as functions of vertical and longitudinal stiffness are also presentable. As illustrated in Figure 12A, an increase in vertical stiffness in the ballast material has no significant effect on the buckling temperature. This is because of the willingness of the rails to displace laterally, with minor lateral moment of inertia. In Figure $12 \mathrm{~B}$ also, it is shown that increasing the longitudinal stiffness of the ballast material from zero to $10000 \mathrm{KN} / \mathrm{m}$ will grow the buckling temperature from 
59.20 to $59.40^{\circ} \mathrm{C}$ in curved track which is ineffective. This growth is due to the prevention of the ballast material from track longitudinal movement and a little counteraction of exerted axial forces in the rails(Figure 12).

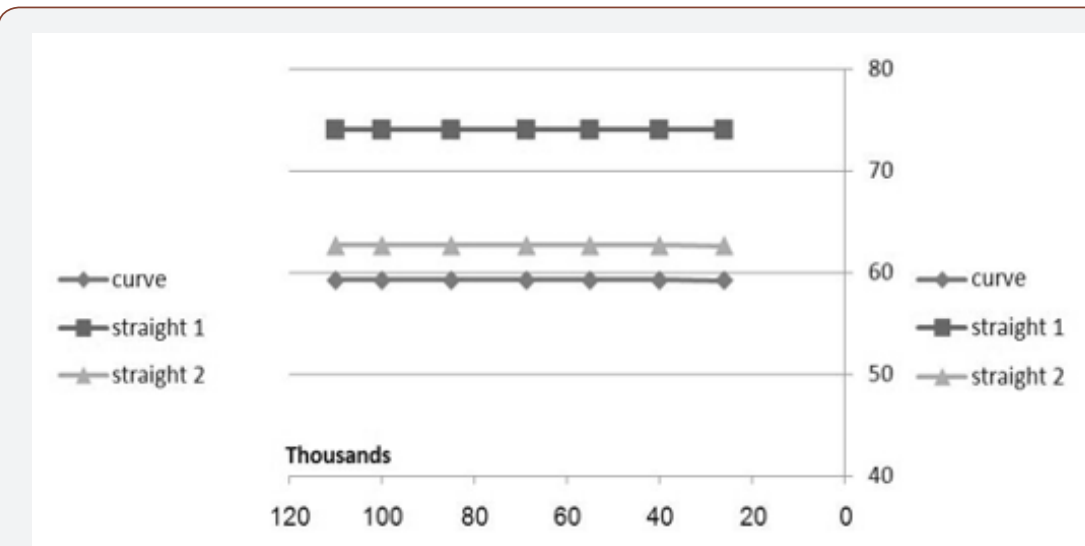

A

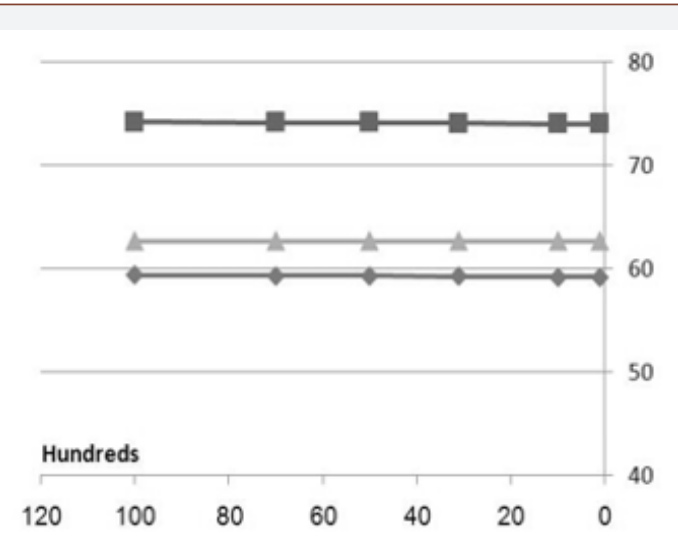

B

Figure 12: Buckling temperature vs. ballast stiffness A) vertical B) longitudinal.

\section{Conclusion}

In this paper, by the application of a code developed in the ANSYS software for determining the buckling temperature of rail tracks, numerous analyses and parametric studies were done on the superstructure components and the effects of each parameter were described individually. The results show that some parameters such as the type of sleepers, the torsional stiffness of fastening systems and also vertical and longitudinal stiffness of the ballast material have no significant effect on the buckling behavior of the track. On the other hand, lateral resistance of the ballast material and the types of rails influence highly the buckling temperature and hence should be considered accurately in the design stages. This is especially very important for newly constructed tracks with lower lateral resistances (i.e. lower than $14 \mathrm{KN} / \mathrm{m}$ ) and also in the curves with small radii. Hence, the required measures should be considered for achieving suitable lateral resistances in critical conditions.

\section{Acknowledgement}

None.

\section{Conflict of Interest}

No conflict of interest.

\section{References}

1. Kish A, Samavedam G (2013) Track buckling prevention: theory, safety concepts, and applications (No. DOT/FRA/ORD-13/16). Federal Railroad Administration, U.S. Department of Transportation, USA.

2. Lim NH, Sung IH (2004) Thermal buckling behavior of continuous welded rail track. Int J Steel Structures, Korea Society of Steel Construction, 4(2): 111-119.

3. Hong S, Jung H, Park C, Lee H, Kim H, et al. (2019) Prediction of a representative point for rail temperature measurement by considering longitudinal deformation. Proceedings of the Institution of Mechanical Engineers, Part F: Journal of Rail and Rapid Transit, USA.

4. Nguyen MN, Wang X, Wang CH (2012) A reliability assessment of railway track buckling during an extreme heat wave. Proceedings of the Institution of Mechanical Engineers, Part F: Journal of rail and rapid transit, USA.

5. Takahashi R, Hayano K, Nakamura T, Momoya Y (2019) Integrated risk of rail buckling in ballasted tracks at transition zones and its countermeasures. Soils and Foundations 59(2): 517-531.

6. Esmaeili M, Khodaverdian A, Neyestanaki HK, Nazari S (2016) Investigating the effect of nailed sleepers on increasing the lateral resistance of ballasted track. Computers and Geotechnics 71: 1-11.

7. Esmaeili M, Hosseini SAS, Sharavi M (2016) Experimental assessment of dynamic lateral resistance of railway concrete sleeper. Soil Dynamics and Earthquake Engineering 82: 40-54.

8. Pucillo Giovanni Pio (2019) Train-Induced Load Effects on the Thermal Track Buckling. In 2019 Joint Rail Conference. American Society of Mechanical Engineers Digital Collection, USA.

9. Sung WP, Shih MH, Lin C, Go CG (2005) The critical loading for lateral buckling of continuous welded rail. Journal Zhejiang University Science 6(8): 878.

10. Zakeri JA, Barati M, Mohammadzadeh S (2018) New Definition of Neutral Temperature in Continuous Welded Railway Track Curves. Periodica Polytechnica Civil Engineering 62(1): 143-147.

11. Allen DH, Fry GT (2018) Method for Predicting Thermal Buckling in Rails. Texas A\&M University, USA.

12. Choi DH, Na HS (2010) Parametric Study of Thermal Stability on Continuous Welded Rail. International Journal of Railway, 3(4): 126-133.

13. Lim NH, Park NH, Kang YJ (2003) Stability of continuous welded rail track. Computers \& Structures 81(22-23): 2219-2236.

14. Zhu J, Attard MM, (2015) In-plane nonlinear localized lateral buckling under thermal loading of rail tracks modelled as a sandwich column. International Journal of Mechanical Sciences 104: 147-161.

15. Phillips R, Nucera C, Coccia S, Di Scalea FL, Bartoli I, et al. (2011) Monitoring thermal stresses and incipient buckling of continuouswelded rails: results from the UCSD/BNSF/FRA large-scale laboratory test track. Proceedings of SPIE, International Society for Optical Engineering, USA.

16. Samoilovich YA (2012) Possibility of producing railway rails with increased strength and minimum buckling. Metallurgist, 55(11): 903911.

17. Mirza O, Kaewunruen S, Dinh C, Pervanic E (2016) Numerical investigation into thermal load responses of railway transom bridge. Engineering Failure Analysis 60: 280-295. 
18. Markine VL, Esveld C (1999) Analysis of lateral behavior of a railway track structure using an optimization technique. Report 7-99-1241, Laboratory for Rail and Railway Engineering, Delft University of Technology, USA.

19. Yun KM, Bae HU, Moon J, Kim JJ, Park JC, et al. (2019) Quantification of ballasted track-bridge interaction behavior due to the temperature variation through field measurements. NDT \& E International 103: 8497.

20. Koike Y, Nakamura T, Hayano K, Momoya Y (2014) Numerical method for evaluating the lateral resistance of sleepers in ballasted tracks. Soils and Foundations 54(3): 502-514.
21. Moghadasnejad F, Nejad seifi V (2007) Investigation on stability of Continues Welded Rail Tracks. MSc. thesis, Amirkabir University of Technology, Iran.

22. Zakeri JA, Karimi S (2009) Investigation on CWR longitudinal forces with application of finite-element method, MSc. thesis, School of Railway Engineering, Iran University of Science \& Technology, Iran.

23. Van MA (1997) Lateral Buckling of Continuous Welded Rail Track due to Thermal and Vertical Loading. 6th International Heavy Haul Conference, pp. 333-343. 